\title{
E-Pharmacy in India During COVID-19 Pandemics: A Study on Digital Marketing Perspective
}

\author{
Dr. Sridevi Maganti ${ }^{1}$, Mr. B VenkaiahappalaSwamy ${ }^{2}$, Mrs. Samanthula Likhitha ${ }^{3}$ \\ ${ }^{1}$ Assistant Professor, Dept of Commerce and Management Studies, \\ Adikavi Nannaya University MSN Campus, Kakinada, A.P. \\ ${ }^{2}$ Assistant Professor and Course-coordinator, Dept of Computer Science, \\ Adikavi Nannaya University MSN Campus, Kakinada, A.P. \\ 3Asst Professor, Dept of Pharmacy, Pydah College of Pharmacy, Kakinada, A.P.
}

\begin{abstract}
Before 16 months, no one in India was aware of the corona virus (COVID-19), but now this virus has spread to almost every country, particularly India, where it infected 25,341,839 individuals, resulting in 279,919 fatalities and 21,754,130 recoveries (as on 18th May,2021, Source-Worldometer information). The COVID -19 pandemic has now entered a hazardous phase of the second wave, demanding a global relockdown. The economy of all nations is experiencing a significant slowdown; rapidly declining stock markets, transportation limitations, a shortage of supplies, and unemployment are the key concerns globally. The epidemic has caused the healthcare systems of countries all across the world to collapse. Due to the fear of becoming infected with the Corona virus and the need to preserve physical distance, most individuals are turning to internet purchases during the lockdown time. Purchasing drugs using a digital platform is not an exception owing to the simplicity of access in one click with safety during the COVID-19 epidemic. E-pharmacies, in collaboration with offline pharmacies, have played a significant role in assisting the nation in its fight against the COVID-19 epidemic 24 hours a day, seven days a week. Online marketing and internet marketing are other terms for digital marketing. Because of the ease, online drug purchases are becoming increasingly popular throughout the world. Companies offer everything marketing from prescriptions to other healthcare supplies on internet websites. The Indian healthcare sector is expanding rapidly, and both online and offline pharmacies are now in operation. The Indian pharmacy business is massive, estimated by industry to be worth over Rs 1.2 lakh crore, and the internet pharmacy sector, believed to be a fraction of that at Rs 700-800 crore, has been hampered by regulatory hurdles that are finally beginning to ease. (2017, Economic Times) The expansion of Internet businesses poses a significant challenge to these traditional businesses. This paper focusses on E-Pharmacy and digital marketing in COVID pandemics from many perspectives.
\end{abstract}

Keywords: COVID-19 pandemic, E-Pharmacy, medical practitioner, Digital marketing, Consumer perspectives, etc.

\section{INTRODUCTION}

Digital marketing is highly prevalent these days, with almost all businesses promoting their products and services using digital technology. Online marketing and internet marketing are other terms for digital marketing. Because of the ease, online drug purchases are becoming increasingly popular throughout the world. The Indian healthcare sector is expanding rapidly, and both online and offline pharmacies are now in operation.

With the increased spread of e-commerce and Internet use, there is an ever-increasing demand for mail-order pharmaceuticals. Many online pharmacies, often known as e-pharmacies, throughout the world provide doorstep delivery as well as the dispensing of prescription medications and over-the-counter items. However, ordering and distributing a prescription medicine through the online need a prescription from a medical practitioner. Patients do not need to visit the pharmacist because of the order of onset of e-pharmacy. The worldwide e-pharmacy market was worth USD 49,727.7 million in 2018 and is expected to be worth USD 177,794.9 million by 2026, growing at a CAGR of 17.3 percent during the forecast period (2019-2026) (Image courtesy of Fortune Business Insights)

Furthermore, leading e-pharmacy firms provide drugs at lower prices than traditional brick and mortar pharmacy stores. The e-pharmacy industry is expected to develop at a CAGR of 17.3 percent over the next 6-7 years, owing to increased investment by e-commerce behemoths in the sector of health care.

The COVID -19 epidemic has reached an unpredictable stage and has brought the economies of all nations to a halt. Declining financial markets, mobility restrictions, a shortage of supplies, and unemployment are the key difficulties 


\title{
IARJSET
}

\section{International Advanced Research Journal in Science, Engineering and Technology}

Vol. 8, Issue 6, June 2021

\author{
DOI: $10.17148 / I A R J S E T .2021 .8628$
}

globally as a result of the COVID-19 pandemic lockdown. The epidemic has also harmed the world's health-care system. The COVID-19 epidemic has necessitated a shift in thinking in order to limit public interaction and reduce transportation. As a result, digital and e-services become increasingly important in the COVID-19 pandemic situation. Purchasing drugs via digital platforms is also increasing owing to the convenience of access in one click with safety during the COVID-19 epidemic.

E-pharmacies in conjunction with existing pharmacies have played a vital part in assisting the nation in COVID-19 pandemic battles for 24 hours a day, seven days a week. Despite the fact that frontline staff were publicly exposed to the virus, E- Pharmacies worked around the clock to maintain services available and to ensure that the public's health care requirements and medications were met in a safe manner.

During the pandemic, India's e-pharmacy business has seen excellent development. According to Dharma Sheth (Founder of Pharma Easy), the demand for medicines for cold, flu, and cough increased on online platforms during the COVID-19 epidemic because people wanted to maintain supply of these drugs available regardless of whether patients required them or not.

The home ministry of India has identified e-buying of medications as a crucial service during the pandemic, which has strengthened the E-Pharma industry in the COVID-19 pandemic. The market share of the Indian E-Pharma business was 20 billion dollars in 2019, with addressable pharmaceuticals accounting for 47 percent of the share, which is expected to increase to 60 percent by 2023. (Source: Statista, a statistics source) Pharm easy Med life, 1MG, Net meds Myra, CareOnGo, and Pharma safe are major online pharmacy firms that are doing electronic marketing. Med Life is the industry leader in India, accounting for over $30 \%$ of the overall online Pharma industry.

In India, e-pharmacy is still in its early stages, with most items available through various shopping sites such as Amazon, Flipkart, Snapdeal, and others. In India, online pharmacies are still in their early stages, but they have the potential to grow into a significant sector in the coming years.

\section{LITERATURE REVIEW}

Singh, H., Majumdar, A., and Malviya, N. (2020) analyzed the fundamental difficulties and obstacles associated with online pharmacy and how it may benefit society and the pharmaceutical industry in a pandemic crisis. The researcher investigated the influence of E-Pharmacy on society in COVID-19, the pharmaceutical sector in a pandemic condition, and the influence of COVID-19 on the pharmaceutical sector.

Saraswat S, Jain R K, and Awasthi S. (2020) analyzed the benefits and drawbacks of controversial online pharmacies in India for people's health. The researcher stated that the government should focus on the creation of legislative and regulatory frameworks to supervise the activities of online pharmacies in order to overcome the challenge provided by online pharmacies to Indian patients, limit risk, and improve benefits. The FICCI E-Pharmacy white paper-E-Pharmacies at the COVID-19 frontline (August 2020) explored digital health in India - Need of the Hour. They also expanded on the consumer view on purchasing drugs during a pandemic, trends toward E-Consultation during a pandemic, and the government's policy on E-commerce during a pandemic. FICCI-ePharmacy-Whitepaper.pdf (http://ficci.in/spdocument 123316/FICCI-ePharmacy-Whitepaper.pdf). The influence of COVID-19 on the e-Pharma Industry was explored in the E-Pharmacy Market Global Research Report 2020. According to the analysis, the E-Pharmacy industry would grow at a rapid pace between 2020 and 2025. The report also examines the effects of COVID-19 on the global economy and the EPharma business. (https://marketresearchfuture.com/reports/epharmacy-market-6615)

S. Priya Nair and Anil Middha (2019) reported the outcomes of a survey on examining the online medicine purchase habits of young people across India, as well as their understanding and perceptions about e-pharmacy. According to (Shankar et al. 2011), clients today use social media such as Twitter, Facebook, Myspace, and LinkedIn, among others, and rely on them for marketing and purchasing decisions, therefore advertising through these channels has become critical. According to Curran et al. (2011), social media sites such as Facebook are a lot better alternative than other advertising techniques since they keep information on their consumers. Web marketing offers various advantages that help them work better, such as "24-hour online; multimedia compatible; worldwide available; interactive; micromarketing compatible; integration ready" (Rowley, 2004). Winer (2009) also mentioned the possibility of advertising on blogs.

Today's internet growth has created new business methods, one of which is social media, such as online communities ( $\mathrm{Lu}$ et al.2010). The availability of the internet has provided users with several opportunities to utilize social media, and they may utilize and engage via email, Twitter, and Facebook without the need for physical interactions (Gruzdet al.2011). Companies now offer prescription medication as well as other healthcare-related items on their websites, and purchasing medication online is a common occurrence.

However, there are a few rogue stores that market unlawful medicines and unlicensed medications. Jacobian (2014) The purchase of drugs online also saves money owing to fewer overhead expenses (Anand\& Sethi,2010) WHO has previously warned against acquiring pharmaceuticals if there are no effective norms and regulations in place to protect public health and people (Siegel,1997). According to (Ovaskainen,2001), WHO is very worried about online sales that may avoid national drug regulatory bodies, allowing unapproved, counterfeit, hazardous, or ineffective medical items to enter the 


\section{IARJSET}

\section{International Advanced Research Journal in Science, Engineering and Technology}

Vol. 8, Issue 6, June 2021

DOI: $10.17148 /$ IARJSET.2021.8628

market. George (2009) conducted research on internet pharmacy and advocated a worldwide regulatory framework. He described an incidence in which Internet pharmacies sold medications and medical services over the internet. The role, obligations, and liabilities of ecommerce in the marketplace, as well as product sellers, must be clearly stated (Alamelu \& Amudha ,2016). Increasing internet and smart phone users demonstrate that India has a promising future in online pharmacy, but with certain obstacles and opportunities (Priyanka \& Ashok,2016).

\section{OBJECTIVES OF THE STUDY}

The study aims to accomplish the following objectives:

1) To investigate and assess the existing state of both offline and online pharmacies

2) To investigate the effects of the COVID-19 epidemic on the Indian online pharmaceutical market.

3) To address the problems that pharmaceutical businesses encounter when attempting to promote online.

4) To determine the pharmaceutical online marketing strategies used by worldwide corporations.

\section{RESEARCH METHODOLOGY}

The data obtained is descriptive. Secondary study was carried out to examine the impact of E-Pharmacies and how firms are digitally promoting their drugs during the COVID-19 pandemic. Secondary sources, such as published articles, journals, newspapers, reports, books, and websites, are used to gather information and data for the research.

\section{DIGITAL MARKETING IN INDIAN PHARMACEUTICAL INDUSTRY}

In the Indian pharmaceutical sector, digital marketing is still in its early stages. Pharmaceutical enterprises are utilizing technology-based services to assist patients in learning more about their diseases and monitoring their health. It may also be important to provide physicians with information on the patient's health and any adverse effects from any particular product. These digital platforms also make it easier for doctors to interact with patients about specific health issues. Digital marketing has clearly simplified advertising, campaign structure, and mass reach at low cost and efficient approaches. Medical medications are used all around the world.

Pharmaceutical businesses are working hard to stay up with the changes brought about by digital technologies. The use of digital marketing in this industry has allowed corporations to adopt a fresh strategy to connecting with customers, physicians, and caregivers in recent years. Mobile communications, advanced analytics, the internet, and the cloud are just a few of the technologies that are transforming the healthcare industry. Despite the fact that most Indian organizations have limited their usage to developing corporate image, updating treatments, simple diet advice, nutrition, exercise, and so on. Nutraceuticals have a fairly aggressive distribution strategy, with just a few corporations involved in the industry. Over and above the Counter.

\section{TYPES OF DIGITAL MARKETING:}

1. Search engine optimization: When customers search for the most popular search engines, they initially go to Google, Yahoo, or MSN/Bing. One of the most prevalent hobbies among internet users of all ages is searching for health information. Search engines are the most common approach for 47 percent of online visitors to discover items or information. Other firms utilize SEO to guarantee their sites appear high on the list, as the top 10 search results receive 78 percent more views than trailing listings. SEO strategies evolve on a daily basis. Search rankings are altered with the use of search engine optimization tactics, which increase the search ranking of Google or any other search engine. This is a massive potential for organizations who employ Search Engine Optimization (SE0) tactics to reach their target consumers. Organizations who do not appear in search engines miss out on a huge opportunity to contact their target audience. The use of keywords in titles and URLs, internal links from your own page, backlinks from other pages, correct image tag usage, and social network activity are all crucial parts of search engine optimization.

2. Pay Per Click Ads: If the company's website receives inadequate traffic, ads can be purchased from Google. Announcements can also be found on other blogs and through ad networks. Pay-per-click (PPC) advertisements are based on the keywords entered into Google's search engine. The customer will use Ad Analytics software to assess the success rate of PPC ads. The client only charges if a user hits the attach button.

3. Social Media Marketing: Social media activity is used as a marketing strategy by search engines. Facebook shares, Twitter retweets, and Google+1 boost your ranking on search engine results pages. 


\section{International Advanced Research Journal in Science, Engineering and Technology}

Vol. 8, Issue 6, June 2021

DOI: $10.17148 /$ IARJSET.2021.8628

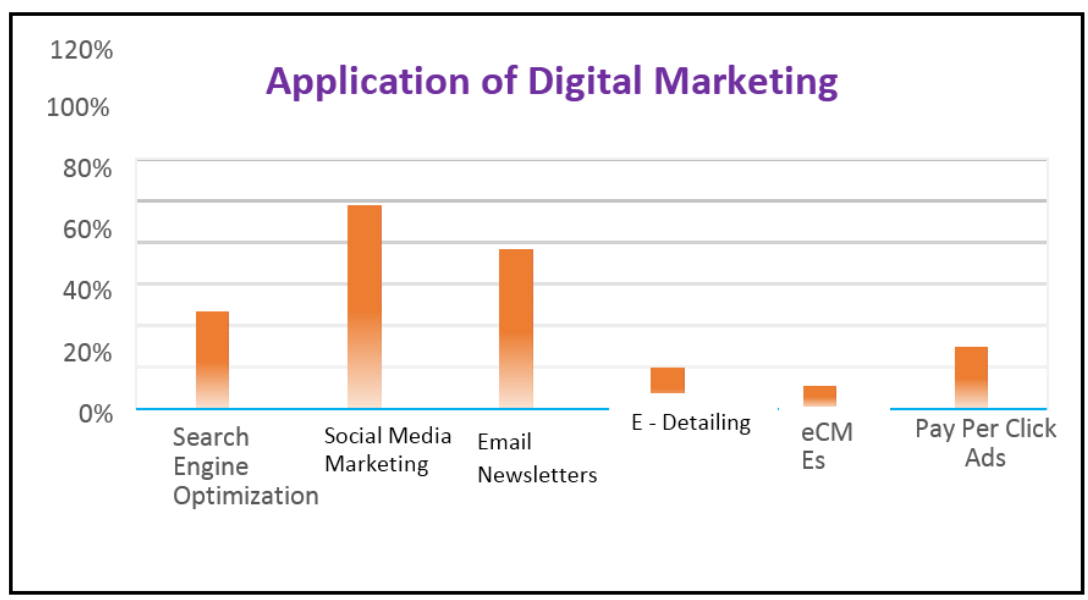

Social media marketing helps the firm to communicate directly with its customers. This reinforces business ideals and enhances the organization's image. Negative experiences can be overcome in the public domain through the distribution of organization website notifications and debate. Social media usage has influenced modern life, particularly pharmaceutical marketing and the healthcare sector. Almost all of the study's participants (97.8 percent) were active social network users, which corresponds to the impact of social media development in the United States as defined by Moorhead et al.

4. Email Newsletters: According to ExactTarget's 2012 User Preference Survey, email is still the first direct channel that customers will select for everyday use, both for customer and marketing communications. Smartphones and tablets, on the other hand, are widely utilized and allow users to swiftly access their emails. In fact, 77 percent of clients prefer to receive authorization-based marketing messages via email rather than social media (6\%) or SMS messaging (5 percent). Email provides customers with a sense of control and personalization by allowing them to choose for a discussion and then only receive the information they choose.

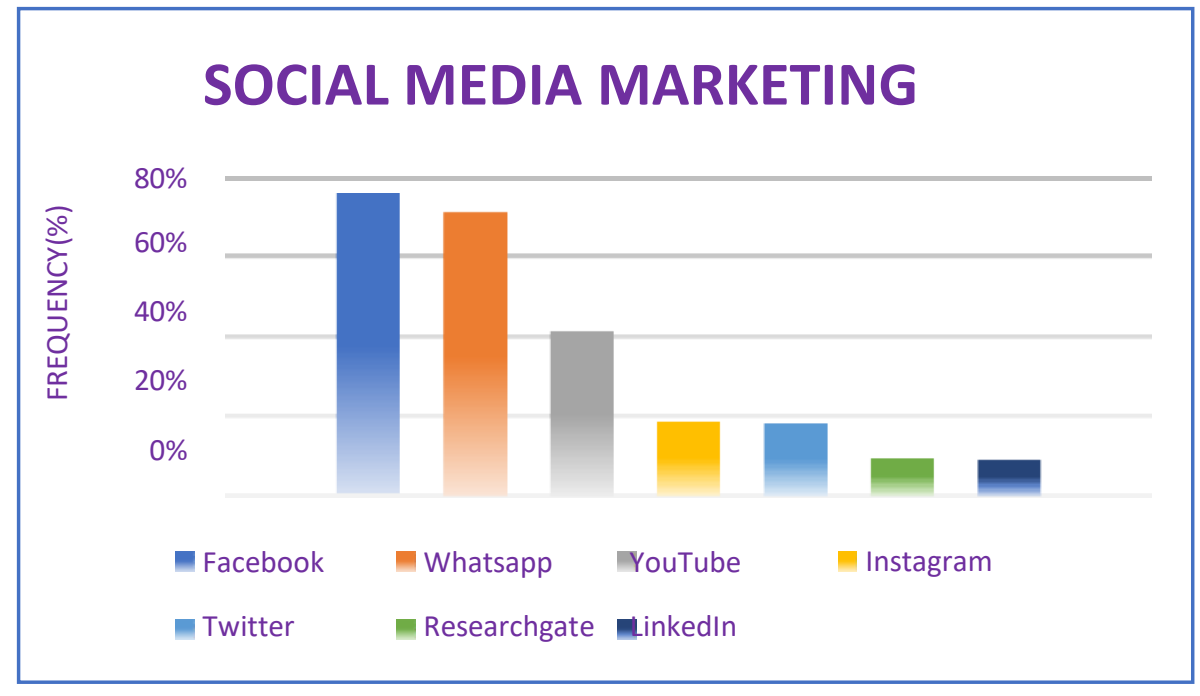

5. $\quad$ E - Detailing: The Indian industry has yet to be fully accepted. In India, there are very few enterprises that are active players in the e-commerce business. While the sales force was first cautious of e-details, wondering whether marketing online would render the traditional sales call obsolete, most members experienced the opposite effect: e-details actually boost the overall time they spend with the rep.

6. eCMEs (electronic continuing medical education) / Webinars: Hybrid meetings are events which combine live and virtual elements. These are also great opportunities and one of the most important developments in the preparation of events. Live broadcasting by means of streaming video of a conference will enable event organizers and organizing organizations, including people following the conference online, to extend their meeting visibility. This is one of Indian Pharmaceutical Industry's most cost-effective strategy 


\section{IARJSET}

\section{International Advanced Research Journal in Science, Engineering and Technology}

Vol. 8, Issue 6, June 2021

DOI: $10.17148 / I A R J S E T .2021 .8628$

\section{CURRENT PHARMACEUTICAL DIGITAL MARKETING SCENARIO AND CHALLENGES}

In 2019, the world's estimated internet user population was 4.48 billion, led by 560 million users in India and 802 million users in China, and continues to grow on a daily basis. This has provided a significant boost to the digital era in a variety of areas.

In any industry, digital marketing is a more cost-effective and time-efficient technique of engaging with customers than conventional marketing. Pharmaceutical marketers may leverage data from digital marketing to establish more strategic interaction with prescribers and physicians. Nonetheless, many businesses are still unable to integrate digital into their whole company's strategy. The pharmaceutical industry is encountering a number of challenges in applying digital marketing tactics, some of which are mentioned below.

1. Inadequate organizational vision: Most firms lack a suitable vision for introducing digital marketing tactics. The techniques are not well defined, accepted, or shared publicly. Good management is required to confirm the vision, define targets, and monitor operational quality. Companies typically do not have a field force or marketing advocates who support the digital pharmaceutical concept.

2. A scarcity of digital minds: There is a scarcity of skilled workers in the pharmaceutical industry who want to lead digital transformation. To build digital marketing within the firm, employees should be familiar with digital marketing as well as the challenges of digital adoption in the pharmaceutical sector. Most businesses need effective personnel that knows both the sector and the new digital market.

3. A digital disaster: While many pharmaceutical businesses have begun to integrate digital channels and campaigns, marketers in this industry are unable to develop an overall successful digital strategy. Improved data lead to more complex studies, and the use of data in digital ways resulted in a worldwide disaster. Pharmaceutical marketers will consolidate data across platforms, utilize data in real-time, and adjust digital ads appropriately utilizing their digital minds. 4. Strict Legislation: Before embarking on any digital project, the regulations in each jurisdiction must be thoroughly reviewed. In comparison to other industries, life sciences marketing is subject to more stringent rules. From privacy to creative copy, the pharmaceutical industry must adhere to the standards of both the FDA and the Federal Trade Commission (FTC). The establishment of the Health Insurance Portability and Accountability Act (HIPAA) in 1996 ensured the protection and privacy of health data. The act prohibited advertising from digitally abusing health data, safeguarding the integrity of health care records. In 2010, the FDA issued a warning letter to Novartis, ordering them to withdraw their Facebook stake because there was insufficient risk disclosure regarding the Tasigna leukemia treatment medicine. Because of the search constraints, pharmaceutical corporations have been more reluctant about investing in and implementing new digital marketing methods. Real-time digital work may be done in industries that are capable of mixing digital and the approval process with built-in regulatory protocols.

5. Poorly maintained websites: Biopharmaceutical manufacturers' usage of social media is slow. Some pharmaceutical businesses are still stuck in the era of "Web 1.0." The pharmaceutical sector has selected one-way information sharing that has been thoroughly studied, legally recognized, and protected from outside intrusion. These websites only transport information that is inaccessible through direct patient engagement. An out-of-date, poorly managed website is worse than none at all. Human resources that are efficient must find a way to handle these relationships.

The following are a few strategies that pharmaceutical companies might use to improve their prospects in the digital world:

1. The introduction of mobile apps: The FDA published rules for mobile medical applications, which alleviated the pharmaceutical industry's protracted wait. In one fell swoop, mobile applications assist patients in better understanding their diagnosis and medications before they are issued. Apps that enable better direct marketing to clients can offer detailed information on any medicine. Pharmaceutical businesses would be more profitable if they partnered with firms that could supply apps in the context of patient management, including symptoms and drugs, rather than illness management.

2. Collaborative business model: Despite its traditional barriers, the pharmaceutical sector is rapidly developing through collaboration with and outside its partners. Because of the availability of digital technology, comprehensive cooperation is now feasible. Workers can work successfully and efficiently to discover new medicines. Pfizer, for example, has created a groundbreaking cloud-based clinical data platform to gather, evaluate, and analyze patient data in clinical trials and medical programs, as well as to aid in smart test design, precision medicine, pharmacovigilance, and regulatory inquiries.

3. Data sharing in population studies: Extensive data collection over time looks to be inefficient if not assessed. The data's findings should be disclosed. The integration of point, mobile, and analytical content will constitute the true digital healthcare change.

4. Ensure enough IT support: To overcome digital marketing difficulties, enough IT help is essential. 


\title{
IARJSET
}

\section{International Advanced Research Journal in Science, Engineering and Technology}

Vol. 8, Issue 6, June 2021

\author{
DOI: $10.17148 / I A R J S E T .2021 .8628$
}

5. Establish a new organizational structure for digital marketing: Appoint an e-marketing strategy manager, an emarketing product manager, a digital marketing committee, and so on to assist in boosting firm digital marketing innovation and developing digital strategies.

6. Business partners: Partnerships with firms that deal with complementary disease characteristics are part of digital initiatives. Businesses selling anticoagulants for atrial fibrillation, for example, could collaborate with medical equipment companies that use remote cardiac monitoring to identify such patients. It is not difficult to implement a digital marketing strategy.

7. Patient and Healthcare Provider Services (HCPs): HCPs are also required to give patients with technologybased services that may assist patients with quality monitoring and administration by utilizing more software on a regular basis. These services can also make a significant contribution to the research and development of novel medicines. It also links partners from the larger healthcare community in order to assist and demonstrate outcomes. Digitally enabled patient services, such as applications or online platforms, or educational materials linked to a broader range, should be employed to aid patients and HCPs coping with health challenges.

\section{THE INDIAN ONLINE PHARMACEUTICAL SECTOR DURING THE COVID-19 PANDEMIC}

People turned to the E-commerce business owing to the cheaper, quicker, and safer form of purchasing than traditional businesses during the new corona virus epidemics. It is not an unusual to buy medicines and health care goods online. For example, once the lockdown was announced in March 2020, 1mg (Leading E-Pharmacy) had a 100 percent increase in order in the first 3 to 4 weeks. Prashant Tondon stated that the demand growth rate at the end of June 2020 was $40 \%$ higher than before COVID (Cofounder of $1 \mathrm{mg}$ ). Throughout the lockout, Digi Prex (a digital subscription platform for patients with chronic diseases) recorded a 100 percent increase in sales.

True med, another online pharmaceutical platform provider, has seen a 35 to $40 \%$ increase in orders month over month during the pandemic, according to Akshay Nayyar (Cofounder, True med). According to the FICCI E-Pharmacy white paper, the number of Indian households selecting online pharmaceutical services during the new corona virus pandemic lockdown increased from 2.8 million to 8.8 million. When a lockdown is in effect, purchasing medication online becomes a lot easier and safer choice for the general populace.

Because of the expansion of the E-Pharmacy business, top E-pharma businesses are attempting to enhance their market shares. According to a forecast by Global Professional Services company EY, the online pharma industry will reach $\$ 18.1$ billion by 2023. Amazon, the world's largest e-commerce corporation, has launched online pharmacy services in India. Reliance Retail has acquired the bulk of the shares in the Chennai-based E-Pharma business Net med Pharm simple, which is merging with med life. According to an Indian Express story (August 2020), all of these commercial actions in the online pharma market are the result of people's behavioural change toward the E-Commerce industry amid the COVID-19 epidemic.

\section{FINDINGS}

Recognizing the critical significance of online pharmacies during the COVID-19 pandemic-induced lockdown, the union ministry of central government has considered the E-commerce business to deliver medication and health care items as vital services during the pandemic.(Vide Order No.403/2020 D dated March 24, 2020).Following the Central Government of India's directive, practically all states have issued their own orders declaring internet pharmacies to be vital services during the COVID-19 pandemic-induced shutdown.

The Central Government of India made this decision at the proper moment, which benefits customers by allowing them to buy drugs safely online. During the epidemic, the decision also helped to strengthen the market for online pharmaceutical enterprises.

Recognizing the importance of digitization during the COVID-19 pandemic lockdown, the government launched the Janaushadhi mobile app on 1 May 2020 to give the advantages of the Janaushadhi programme. The Janaushadhi app provides detailed information on drugs, nearby facilities, and scheme data.

The Union Ministry of India has also declared that the e-pharmacy industry is making a substantial contribution to the achievement of national development and digital India. Recognizing the relevance and extent of the digital health care system in the context of the pandemic, we need to build a better digital health care system for the future.

Our country still lacks a properly digitalized healthcare system to assist in such pandemic situations. To capitalize on the promise of E-pharmacy following COVID-19, we will also require a strong regulatory support framework to make the Epharmacy model more failsafe, allowing us to overcome the obstacles experienced by the Indian online pharma industry.

\section{DISCUSSION}




\section{IARJSET}

\section{International Advanced Research Journal in Science, Engineering and Technology}

Vol. 8, Issue 6, June 2021

DOI: $10.17148 /$ IARJSET.2021.8628

In the United States, both online and offline pharmacies are regulated; however, digital pharmacies are only permitted to operate under particular conditions. At the same time, the Food and Drug Administration (FDA) is running a campaign to educate the public about the hazards of purchasing prescription medications online. They also give information on the hazards of purchasing from a fake online pharmacy, how to detect a fake online pharmacy, and how to select a secure online pharmacy. In this way, India may learn from the United States. The Indian government must consider patient information privacy and security when it comes to internet pharmacies. They can educate the general public on the safe procedures of obtaining internet medications. In the future, they may give a list of approved/accredited online pharmacies. Without a doubt, E-Pharmacy enhances customer convenience and access, which will assist senior individuals suffering from chronic illnesses who must visit a pharmacy to purchase medications. At the moment, there is a lot of misinformation concerning e-pharmacies, especially among people who do offline business in this market.

E-commerce is nothing more than a movement in business from the old method and how business will be done in the future, and everyone will have to adjust to the changing trends (FICCI, 2016). According to (FICCI, 2016), e-Pharmacy is just a technological innovation, and thus they advised that it be permitted and its advantages be provided to customers in India by safeguarding and enforcing rigorous regulatory controls to protect the customers' interests. They also advocated that narcotic medications and other habit-forming substances be offered only through an e-Pharmacy model.

\section{CONCLUSION}

At the moment, the top E-pharmacy players are 1mg, Net medicines, MChemist, Myra, med life, and others. Approximately 150 start-ups are presently functioning as online pharmacies. In this regard, India needs an efficient regulatory structure. The goal should be accomplished as soon as possible because additional delay would be detrimental to these service providers and clients. The AICOD and IIPA both have the authority to demand. The government should come up with a reasonable solution that benefits all sides. Because India is such a large country, online pharmacies must exist.

The COVID-19 pandemic has called for a new style of thinking because to mobility restrictions under lockdown and the need to maintain physical distance. Due to the pandemic-induced lockdown, the digital and e-commerce businesses are becoming increasingly vital. E-pharma firms are also developing dramatically as consumers know that purchasing medications online is a safer method to safeguard against infection.

Consumers benefit from E-Pharmacy in lockdown by receiving a consistent supply of medications, hand sanitizers, face masks, and other health care goods in a safe and convenient manner.

Recognizing the potential of the online pharma market in the future (post-COVID), major e-commerce companies such as Amazon and Reliance Retail have begun to invest in the E-pharma business. Because of the comprehensive value proposition supplied by E-pharma firms, historical experiences, and the change to digital platforms as a result of COVID19 , the online pharma business has enormous potential in the future years.

The causes driving the need for e-Pharmacy in India are mostly unfulfilled medical demands as a result of the country's growing population and increased internet usage. As consumer behaviour in India is changing, there is a growing desire for easy access to a diverse selection of items at cheap costs.

\section{REFERENCES}

[1]. Alamelu, R., Amudha, R Motha, L.C.S., \& Nalini,R. Online pharma retail is promising/ unpromising avenue: An Indain context. Asian journal of pharmaceutical and clinical research, 9(2), (2016).

[2]. Antai, M., \& Shukla, A. Indian online pharmacies \& drug stores in legal tug-of-war. eHealth Law \& Policy. Retrieved from http://www. Nishi thdesai.com/fileadmin/user_upload/pdfs/Research\%20Articles/Indian_online_pharmacies_\&_drug_stores_in_legal_tug-of-war.pdf Nov, 2015

[3]. George,C. Internet Pharmacies: Global threat requires a global approach to regulation. Telehealth Law,9(3), (2009).

[4]. http://ficci.in/spdocument/20746/E-Pharmacy-in-India-Last-Mile-Access-to- Medicines_v5.pdf

[5]. Jacobian, E. Advantages and Disadvantages of Buying medicines though online pharmacy. Pharma Science (11), (2014).

[6]. Jain,V. H., Tadvi, S.A. ,\& Pawar, S.P.A REVIEW ON THE PROS AND CONS OF ONLINE PHARMACIES. Journal of Applied Pharmaceutical Research5 (1): $20-26,(2017)$.

[7]. Lu,Y., Zhao, L., \& Wang,B. From virtual community members to c2c e-commerce buyers: trust in virtual communities and its effect on consumers' purchase intention. Electronic Commerce Research \& Applications, 9(4) pp. 346-360., (2010).

[8]. Ovaskainen,H. Internet pharmacies: advantages and risks. WHO Drug Information $15(3$ \& 4), (2001).

[9]. Priyanka, V.P., \& Ashok, B.K. E-pharmacies Regulation in India: Bringing New Dimensions to Pharma sector pharmaceutical regulatory affairs Pharmaceutical Regulatory Affairs 2016,5(2) Retrieved from https://www.omicsonline.org, (2016).

[10]. Rowley, J. Online branding. Online Information Review, 28(2) pp.131-138, (2004).

[11]. Parekh, Dhara, Pankaj Kapupara, and Ketan Shah; „Digital Pharmaceutical Marketing: A Review“, Rexeach Journal of Pharmacy and Tedmogy, 9.1, $108-12,(2016)$

[12]. Kumar, Manoj, and Prof BhausahebLondhe, „Relevance and Impact of Digital Marketing in Indian Pharmaceutical Industry with Specific Reference to Super Specialists Doctors", 7.2, 1-7, (2019)

[13]. Sarma Ranganathan, Smitha, Vishal C Bellani, and Author Smitha Sarma Ranganathan,Digital Marketing in the Indian Pharmaceutical Industry: A Study to Assess Views of Pharmaceutical Marketing Professionals in Using Digital Marketing as a Brand Promotional Lever", World Joumal of Pharmacy and Pharmaceutical Sciences, 5041.4, 2278-4357, (2016)

[14]. Lalitkumar, Prof. Bhole B. Pharm, and Sushma Verma; Digital Marketing: A Road Ahead to Pharmaceutical Selling", 61-65, 2018 


\section{IARJSET}

\section{International Advanced Research Journal in Science, Engineering and Technology}

Vol. 8, Issue 6, June 2021

DOI: $10.17148 /$ IARJSET.2021.8628

[15]. Dhara P, Pankaj K, Ketan S; Digital pharmaceutical marketing: a review. Res J Pharm Technol. 9:108-12. 10, 2016.

[16]. Greene JA, Kesselheim AS: Pharmaceutical marketing and new social media. N Eng J Med., 363:2087-89, 2010.

[17]. Jawaid, Masood, and Syed J Ahmed, „Pharmaceutical Digital Marketing and Its Impact on Healthcare Physicians of Pakistan: A National Survey", Cureus, $10.6(2018)$

[18]. Shankar, V. and Li, J, "Leveraging Social Media in the Pharmaceutical Industry", Springer International Publishing AG, pp.477-505, 2013

[19]. Schultz, D. and Peltier, J, "Social Media's Slippery Slope: Challenges, Opportunities and Future Research Directions", Journal of Research in Interactive Marketing, 7(2), pp.86-99, 2013

[20]. Gupta, P. and Udupa, A, "Social media marketing by pharmaceutical industry: Perception and attitudes of key stakeholders", Business and Economics Journal, 1-8., 2011.

[21]. https://ejmcm.com/pdf_7739_4d2671f15842492459184060a6a78527.html

[22]. "Users Perspectives on Online Pharmacy Model"

[23]. "E-Pharmacy vs. Conventional pharmacy"

[24]. International journal of comprehensive and advance, pharmacology Dec.2018:3(4):121-123)

[25]. Chakraborty, P., Satsangi, A. (2019)

[26]. "Online pharmacy in India-A study on digital marketing perspective"

[27]. E-Pharmacy Market Global Research Report 2020 